\title{
INDIVIDUAL AND AGE DIFFERENCES IN THE SPERMICIDAL EFFECT OF ETHYLENE DIBROMIDE IN BULLS
}

\author{
D. AMIR \\ Division of Animal Reproduction, Agricultural Research Organization, \\ The Volcani Center, P.O. Box 6, Bet Dagan, Israel
}

(Received 20th Fanuary 1975)

It has been reported that the administration of ethylene dibromide, either orally or by injection, to bulls induced malformations in the heads of ejaculated spermatozoa collected from about 3 weeks after the start of the treatment (Amir \& Volcani, 1965; Amir \& Ben-David, 1973). These malformations persisted for about 3 weeks, and then spermatozoa with normal-shaped heads appeared in the ejaculates. Since head malformations in spermatozoa can occur as a result of testis dysfunction (Gustafsson, 1966), it is possible to study the mechanism of sperm formation in the testis by following the various stages of interference by ethylene dibromide in the normal process of spermatogenesis. However, individual differences should be determined before the physiological significance of ethylene dibromide action is considered. In the present study, the release of spermatozoa with abnormal heads from the testis into the epididymis, their appearance and duration of presence in the ejaculates of different bulls were followed.

Nineteen Israeli-Friesian bulls, maintained on a roughage and concentrates ration, were used. Seventeen animals were 15 to 24 months old (young animals) and weighed 400 to $500 \mathrm{~kg}$, and two were $4 \frac{1}{2}$ and 5 years old (adult animals) and weighed 950 and $1050 \mathrm{~kg}$. Thirteen of the young animals and the two adult bulls were treated orally with ten doses, each of $4 \mathrm{mg}$ ethylene dibromide/ $\mathrm{kg}$ body weight. The ethylene dibromide was diluted in olive oil to a concentration of $200 \mathrm{mg} / \mathrm{ml}$ and given in gelatin capsules with a ball-gun on alternate days. Three of the remaining bulls were untreated, and three were treated in the same way and frequency as were the experimental animals, but ten doses of 8 to $10 \mathrm{ml}$ oil were given.

The six treated and six untreated young bulls were castrated or slaughtered 1 day after the last oral dose. Semen was collected from the seven remaining bulls by means of an artificial vagina two or three times per week for 2 months after the start of treatment and once or twice a week thereafter. Sperm concentration was measured with a Klett-Summerson colorimeter, and sperm motility was estimated microscopically, on a warm stage, as the \% of motile cells. Sperm smears were prepared from different parts of one epididymis of the castrated or slaughtered bulls and from the ejaculates of the other seven animals, and were stained with Giemsa. At least 400 spermatozoa were randomly observed on each slide 
under an immersion objective $(\times 1000)$, and those with head malformations were recorded.

In the untreated animals, 2 to $4 \%$ of spermatozoa along the genital tract had misshapen heads (Text-fig. 1). In the treated animals, 1 day after the last dose of ethylene dibromide, the position of the largest proportion of spermatozoa with abnormal heads, mainly pear-shaped, varied in different bulls (Text-fig. 1). According to Orgebin-Crist (1962) the duration of the passage of bull spermatozoa through the caput and corpus epididymidis is about 3 days and 1 day, respectively. Therefore, the variation in the time of release of the abnormal spermatozoa through the vasa efferentia in the six bulls in this study could have been about 4 days.

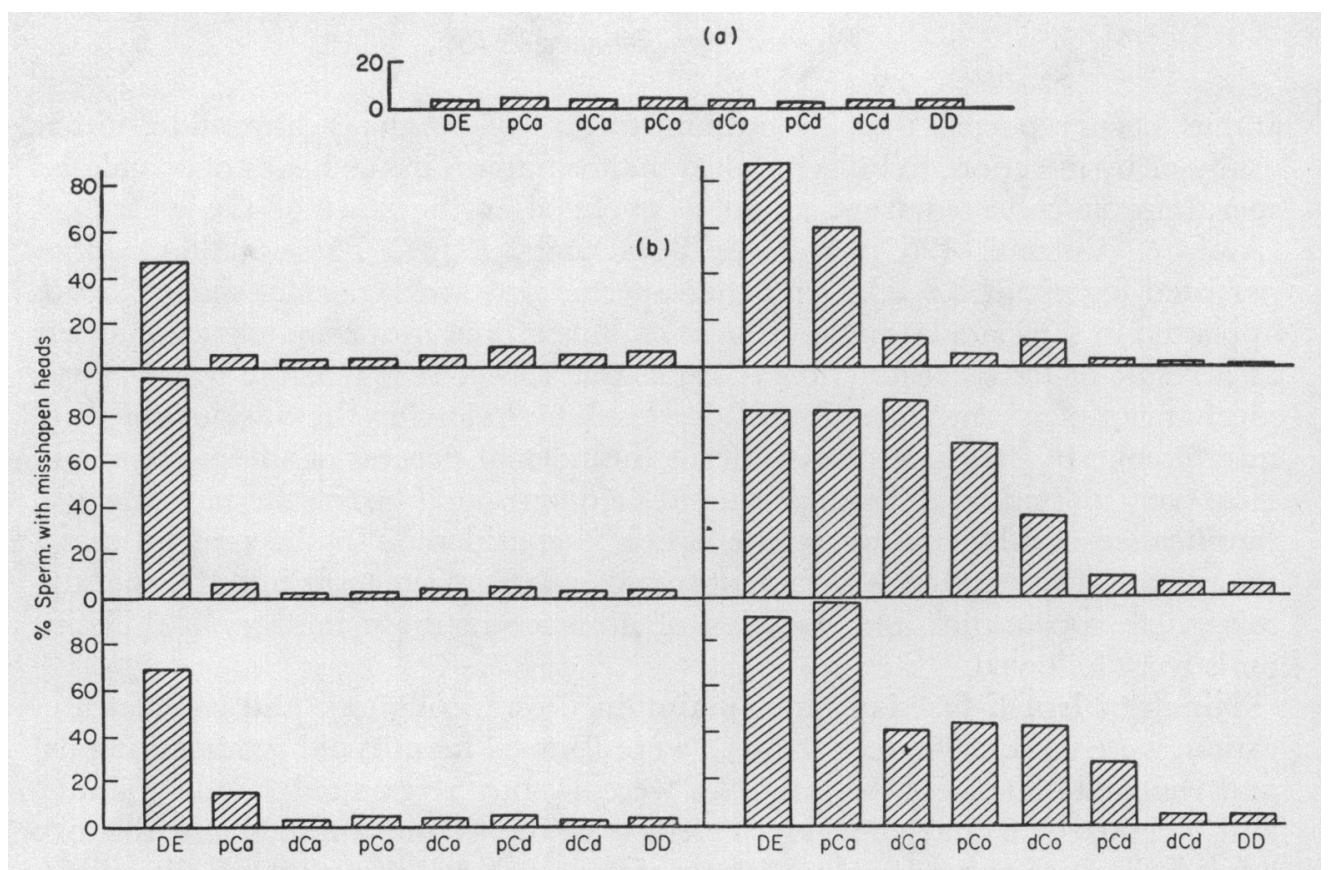

TexT-FIG. 1. The distribution, 1 day after the last oral dose, of spermatozoa with misshapen heads in the genital tracts of (a) untreated bulls, and (b) bulls treated orally with ethylene dibromide (see text). DE, ductuli efferentes; $\mathrm{pCa}$, proximal caput epididymidis; dCa, distal caput; pCo, proximal corpus epididymidis; dCo, distal corpus; $\mathrm{pCd}$, proximal cauda epididymidis; dCd, distal cauda; DD, ductus deferens.

The shape of the sperm head is affected by ethylene dibromide (Amir \& Ben-David, 1973) during spermiogenesis and, if this process was of the same duration in all the experimental bulls, the differences between bulls in the time of release of affected spermatozoa through the vasa efferentia into the epididymis could be the result of individual variations in the dose-response threshold of the bulls. The constancy of duration of the spermatogenic processes in a given species (Courot et al., 1970) has, however, recently been contested for the rabbit (Amann, 1972), in which a 2-day variation in release of labelled spermatozoa from the testis was found.

In the five young bulls, maximum numbers of spermatozoa with misshapen 
heads appeared in the ejaculate from 2 to 10 days after the end of treatment (Text-fig. 2a). These differences could be attributed to the differences in the sperm transit time through the epididymis (Orgebin-Crist, 1962) as well as to the variation in the release time of the affected spermatozoa from the testis (Text-fig. 1).

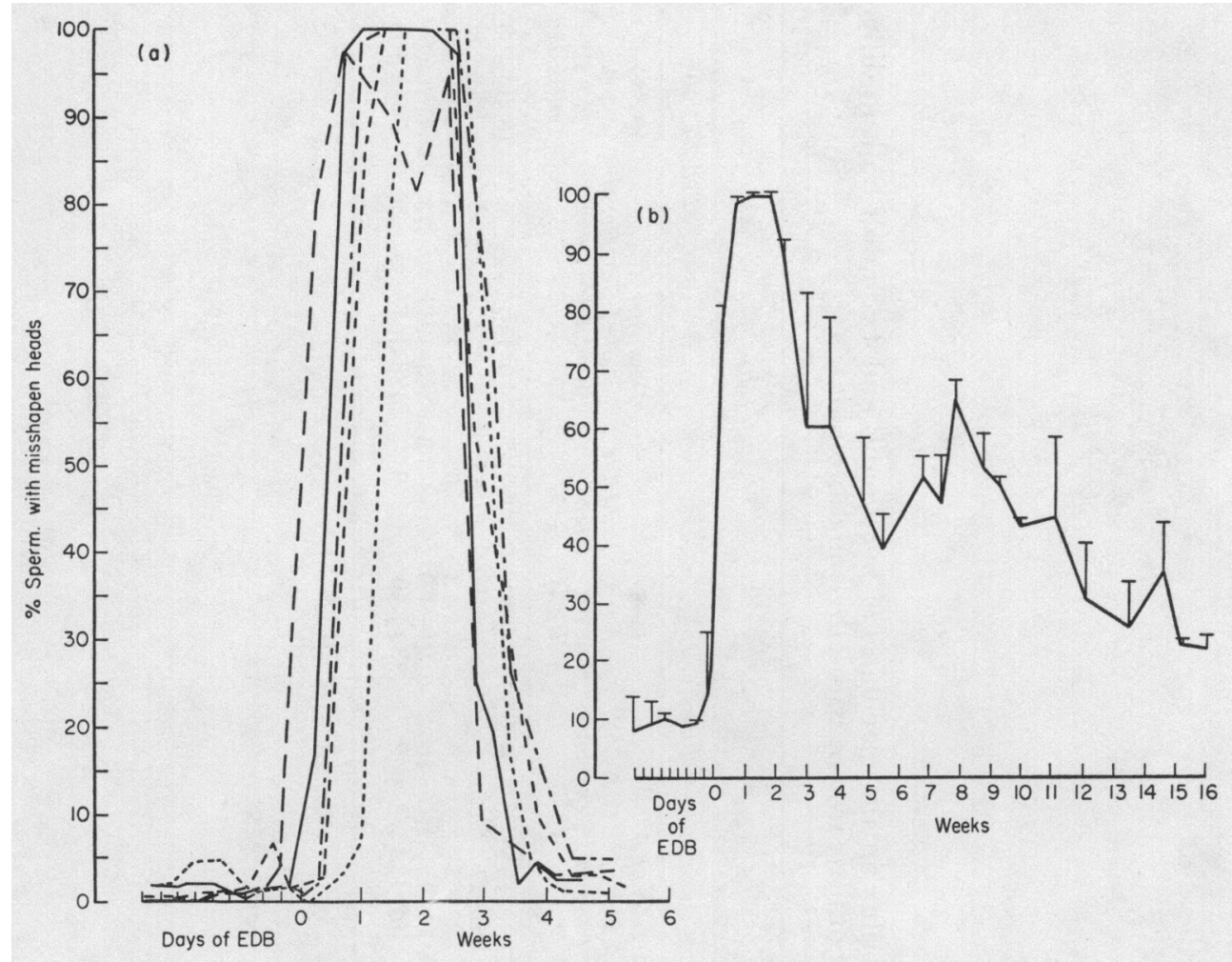

Text-FIG. 2. Changes in the percentage of spermatozoa with misshapen heads in the ejaculates of (a) five young bulls (each bull designated by a different line), and (b) two adult bulls after oral treatment with ethylene dibromide (EDB). Vertical lines indicate the S.E.M. 0, Day of last oral dose (see text for details).

The effect of ethylene dibromide was more acute in the adult than in the young bulls. Sperm concentration in the latter was only slightly affected by the treatment, but decreased in the older bulls (Table 1). Normal sperm concentration was recovered about a month in one bull and about 4 months in the other after the last oral dose. During the period of low sperm concentration the ejaculates of these bulls contained much sperm debris and many germ cells, spermatocytes and spermatids. The sperm debris, which probably resulted from further disintegration of the degenerating spermatozoa found previously in the ejaculates, was disregarded when counting abnormal spermatozoa in the sperm smears. Thus the $\%$ of spermatozoa with abnormal heads was an underestimate and their reduction in numbers was more gradual than that presented in Text-fig. 2(b). The $\%$ of spermatozoa with misshapen heads returned 


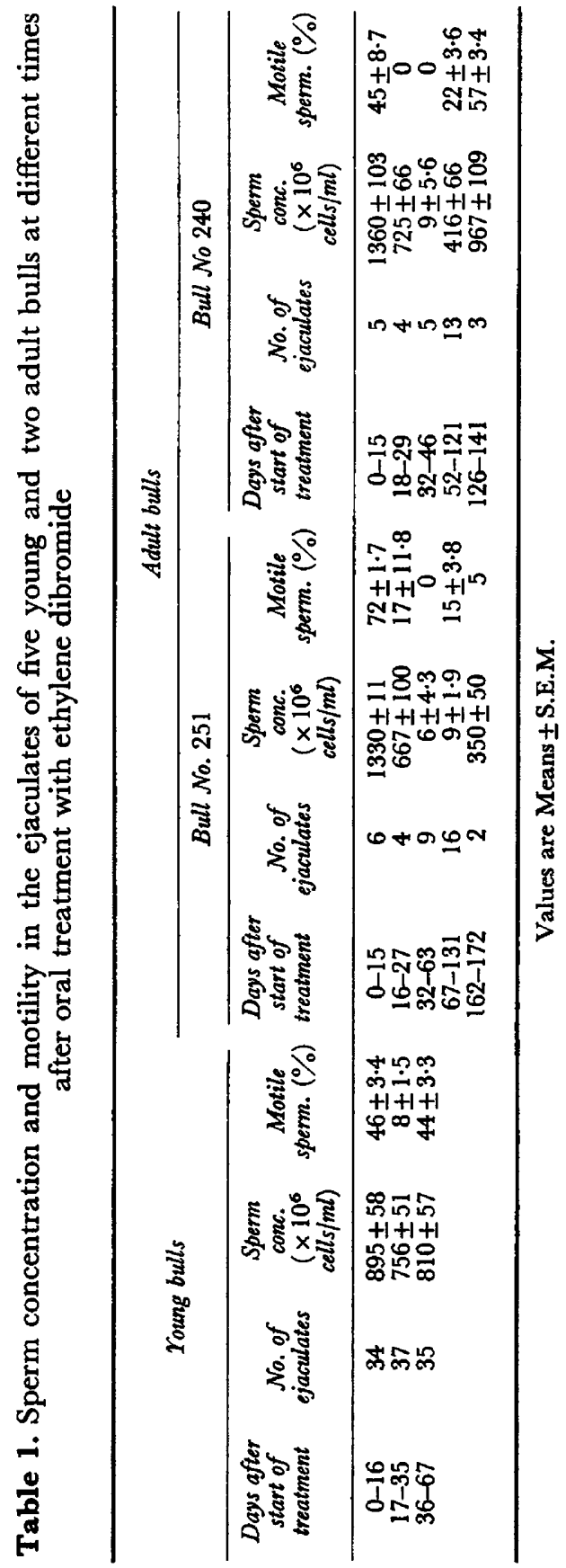


to normal in the young bulls by about 3 weeks, but was still elevated in the two adult bulls about 15 weeks after the end of the treatment (Text-fig. 2).

Since the abnormalities in the sperm heads observed in the ejaculates of young bulls persist for a period which coincides with the duration of spermiogenesis in this animal (about 3 weeks), it was suggested (Amir \& Ben-David, 1973) that ethylene dibromide affects spermiogenesis. From the data obtained in the present study with the adult bulls, it seems that the drug affects earlier stages of the spermatogenic process and/or that its elimination from the circulation of young animals is more rapid. When ethylene dibromide was administered orally for a long period to young bulls, a similar acute effect was recorded (Amir \& Volcani, 1965).

The paper is a contribution from the Agricultural Research Organization, The Volcani Center, P.O. Box 6, Bet Dagan, Israel, Series 1975, No. 110-E. The author is indebted to the Artificial Insemination Center, 'Hasherut', for allowing him to use the two adult bulls in this work. I thank Dr H. Schindler, Dr U. Lavon and Mr R. A. Lehrer for reading the manuscript and their valuable suggestions.

\section{REFERENGES}

AMANN, R.P. (1972) The effect of variations in the duration of rabbit spermatogenesis on determinations of sperm epididymal transit time. Proc. 7th Int. Congr. Anim. Reprod. $\mathfrak{F}^{\circ}$ A.I., Munich 1, 431-435.

AMIR, D. \& BEN-DAvid, E. (1973) The pattern of structural changes induced in bull spermatozoa by oral or injected ethylene dibromide (EDB). Annls Biol. anim. Biochim. Biophys. 13, 165-170.

Amr, D. \& VolaAnı, R. (1965) Effect of dietary ethylene dibromide on bull semen. Nature, Lond. 206, 99-100.

Courot, M., Hochereau-de Reviers, M.T. \& Ortavant, R. (1970) Spermatogenesis. In The Testis, Vol. 1, pp. 339-432. Eds. A. D. Johnson, W. R. Gomes and N. L. VanDemark. Academic Press, New York.

Gustafsson, B. (1966) Luminal contents of the bovine epididymis under conditions of reduced spermatogenesis, luminal blockage and certain sperm abnormalities. Acta vet. scand., Suppl. 17, 1-80.

Orgebin-Crist, M.C. (1962) Recherches experimentales sur la durée de passage des spermatozoïdes dans l'épididyme du taureau. Annls Biol. anim. Biochim. Biophys. 2, 51-108. 